\title{
RELATIONSHIP BETWEEN TRANSACTIONAL LEADERSHIP AND KNOWLEDGE MANAGEMENT
}

\author{
A. Ghanbari*1, M. Abedzadeh ${ }^{2}$ \\ ${ }^{1}$ Department of Management, East Azerbaijan Science and Research Branch, Islamic Azad \\ University, Tabriz, Iran \\ ${ }^{2}$ Department of Management, Tabriz Branch, Islamic Azad University, Tabriz, Iran
}

Published online: 15 May 2016

\begin{abstract}
All leaders do not possess same attitude or same perspective. There are many different leadership styles that can be exhibited by leaders in the political, business or other fields. A leadership style is a leader's style of providing direction, implementing plans, and motivating people. The Transactional style of leadership involves motivating and directing followers primarily through appealing to their own self-interest. Besides, Knowledge management (KM) is the process of capturing, developing, sharing, and effectively using organizational knowledge. It refers to a multi-disciplined approach to achieving organizational objectives by making the best use of knowledge. We knows that the leadership style is directly influential in organization's tendency and manner of facing processes and steps of knowledge management, so in this paper the relationship between Transactional Leadership and Knowledge Management in Plastic Industry in Shiraz-Iran is examined. We've used of descriptive statistics technique to analyze demographic variables and to investigate the hypotheses; we have used Pearson Solidarity Test and Spearman.
\end{abstract}

Keywords: Transactional Leadership, Knowledge Management, Plastic Industry

Author Correspondence, e-mail: Alireza.ghanbari@ hotmail.com

doi: http://dx.doi.org/10.4314/jfas.v8i3s.233 


\section{INTRODUCTION}

Leadership is important for motivating followers and mobilizing resources towards the fulfillment of the organization's mission; it is also essential for organizational innovation, adaptation, and performance. Various models have been proposed as antecedents of leader outcomes with Bass's (Bass,1985) transformational, transactional, and full-range leadership theory being one of the most-researched contemporary theories.(Antonakis\&House ,2014)

Transactional Leadership, also known as managerial leadership, focuses on the role of supervision, organization, and group performance; transactional leadership is a style of leadership in which the leader promotes compliance of his/her followers through both rewards and punishments. Unlike Transformational leadership, leaders using the transactional approach are not looking to change the future, they are looking to merely keep things the same. Leaders using transactional leadership as a model pay attention to followers' work in order to find faults and deviations. This type of leadership is effective in crisis and emergency situations, as well as for projects that need to be carried out in a specific way.

Being a significant factor influencing the leadership style, knowledge is also considered a valuable measure to help the organization gain success (Zhang, Wang, Xiongfei, Wang, \& Zhao, 2012). Recent studies done by Abdul-Rahman and Wang (2010) demonstrate a poor functioning of industries in managing knowledge resulting in an enormous waste of resources and undesired effects to quality. Knowledge management can be regarded as one factor influencing and hence shaping and covering an organization's workforce (Hislop, 2009). It has been proved that knowledge management is an advantageous factor in creating a useful and efficient environment in today's business (Pathirage, Amaratunga, \& Haigh, 2007). The objective of knowledge management is to create an environment for individuals enabling to communicate and exchange knowledge more efficiently (Margaryan, Milligan, \& Littlejohn,2011).

So in this paper the relationship between Transactional Leadership and Knowledge management is examined.

\section{LITERATURE REVIEW}

\subsection{Transactional Leadership}


The transactional style of leadership was first described by Max Weber in 1947 and then by Bernard Bass in 1981. This style is most often used by the managers. It focuses on the basic management process of controlling, organizing, and short-term planning.

According to Burns (1978), "Transactional leadership occurs when one person takes the initiative in making contact with others for the purpose of an exchange of valued things". According to Bass and Riggio (2006), "Transactional leaders are those who lead through social exchange". Yukl (2006) described contingent reward as "...clarification of the work required obtaining rewards and the use of incentives and contingent rewards to influence behavior". Managementby-exception focuses on leadership as a negative behavior. This leadership behavior is when the leader concentrates on the subordinates "deviances, mistakes, and errors and then taking corrective actions as quickly as possible when they occur" (Avolio \& Bass, 2004).

Adhering to the path-goal theory, transactional leaders are expected to do the following:

- "Set goals, articulate explicit agreements regarding what the leader expects from organizational members and how they will be rewarded for their efforts and commitment, and provide constructive feedback to keep everybody on task" (Vera \& Crossan, 2004).

Transactional leaders use reward and punishments to gain compliance from their followers. They are extrinsic motivators that bring minimal compliance from followers. They accept goals, structure, and the culture of the existing organization. Transactional leaders tend to be directive and action-oriented. Transactional leaders are willing to work within existing systems and negotiate to attain goals of the organization. They tend to think inside the box when solving problems Transactional leadership is primarily passive. The behaviors most associated with this type of leadership are establishing the criteria for rewarding followers and maintaining the status quo.Within transactional leadership, there are two factors, contingent reward and managementby-exception. Contingent reward provides rewards for effort and recognizes good performance. Management-by-exception maintains the status quo, intervenes when subordinates do not meet acceptable performance levels, and initiates corrective action to improve performance.(Hackman et al,2009) .

\subsection{Knowledge Management}

Knowledge Management (KM) was introduced about two decades ago to assist companies to create and use knowledge more effectively. 
According to Yang's definition of the term (2011) Knowledge management can be defined as "the process of identifying/creating, assimilating, and applying organizational knowledge to exploit new opportunities and enhance organizational performance".

$\mathrm{KM}$ includes the managerial efforts to enhance the performances of the companies and also to create, store, share, and develop knowledge by individuals and groups (Zheng, Yang,\& Mclean, 2010).

One may associate KM's goals with innovation and knowledge retention in the organization resulting in maximized productivity and hence minimizing cost (Plessis, 2005).

It should be noted that the expected benefits are related to the pre-planned objectives. Several authors consider the measurement of the benefits of $\mathrm{KM}$ as a step in the KM process.(Goldoni \& Oliveira, 2010).

Bukowitz \& Williams model classifies the process of knowledge management into two groups of strategic and tactical. The tactical model includes acquiring appropriate knowledge necessary for the activities, applying knowledge in creating value, learning, exchanging and sharing knowledge among individuals. The strategic model includes acquiring value from tactical model where the organization strategy is applied along with organizational purposes (Smith, 2001).

The unfortunate point about KM is that the literature regarding this topic has not been fruitful through time.

The framework presented in this paper is fundamentally based on the General Knowledge Model Newman\& Conrad in year 1999. The model divides knowledge into four main areas: knowledge creation, retention, transfer and utilization.

1. Knowledge Creation

This factor refers to implementing new knowledge into the system and hence by doing so causing knowledge development, discovery and capture (Newman \& Conrad, 1999).

2. Knowledge Retention

As the name suggests this element allows knowledge to remain in the system once introduced. It also refers to those activities which retain the practicality of knowledge. (Newman \& Conrad, 1999).

3. Knowledge Transfer

Knowledge transfer refers to transferring knowledge from one individual or group to another. This includes communication, translation, conversion, filtering and rendering 
(Newman \& Conrad, 1999).

4. Knowledge Utilization

Again as the name suggests it refers to utilization of knowledge and to make it more practical in business processes (Newman \& Conrad, 1999).

Gelard et al.(2014) used the same framework above, to investigate the relationship between transformational leadership and knowledge management.

\subsection{The relationship of various leadership styles and knowledge management}

Riaz et al. (2014) in a research entitled "Transformational, Transactional Leadership and Rational Decision Making in Services Providing Organizations: Moderating Role of Knowledge Management Processes" indicate that transformational leadership, knowledge management processes, and transformational leadership x knowledge management processes contributed $2.8 \%$ variance in rational decision making. Similarly, transactional leadership, knowledge management processes, and transactional leadership x knowledge management processes contributed 1.7\% variance in rational style.

Gelard et al. (2014) in a research entitled "Relationship Between Transformational Leadership and Knowledge Management" demonstrate a positive relationship between transformational leadership and knowledge management and the amount of solidarity $(0.784)$ is meaningful in alpha level of 0.01 .

Nguyen and Mohamed (2011) strongly suggest that leaders are highly influential in KM practices. What leaders may do to make this factor more influential is to exercise and cultivate their knowledge manipulation skills and also to share their individual knowledge.

Notably, Politis (2001) studied upon the relationship between self-management, transformational/ transactional leadership and different features of knowledge management.

As far as Bryant's research and study on transformational leadership reveals it can be an influential factor in knowledge management skills, though his research does not directly show the causative relationship (Crawford, 2005).

Research Hypotheses are:

H1. There is a relationship between transactional leadership and knowledge management.

$\mathrm{H} 2$. There is a relationship between transactional leadership and Knowledge Creation.

H3. There is a relationship between transactional leadership and Knowledge Transfer.

H4. There is a relationship between transactional leadership and Knowledge Utilization. 
H5. There is a relationship between transactional leadership and Knowledge Retention.

\section{MATERIALS AND METHODS}

The measurement instrument having been applied in this research is a questionnaire consisting of two parts. The first part contains 30 questions relating to different aspect of transactional leadership developed by Bass in 1990. The second part consists of 25 questions analyzing different aspects of knowledge management, and its reliability and validity have been tested to prove its existence in a suitable extent.

The questionnaire also makes use of the five point Likert scale. ( $1=$ very low and $5=$ very high). 290 questionnaires along with a covering letter that explained the purpose of the study were distributed to directors, experts, supervisors and employees of Plastic Industry in Shiraz-Iran. 261 questionnaires indicating a response rate of $90 \%$ were returned. Only eight (8) questionnaires were disposed of because they contained incomplete information.

This process was bias-free. The survey research method which incorporated the use of the questionnaires was applied to obtain the required data from the respondents. Research type is applied; the obtained data were analyzed using descriptive statistical techniques.

To investigate the correlation between variables and because of the abnormal distribution of components of knowledge management and also knowledge retention, we have used the Spearman Correlation and for other variables Pearson Correlation has been used.

\section{RESULT}

Hypothesis number 1: There is a relationship between transactional leadership and knowledge management.

Table.1. Relationship between Transactional Leadership and Knowledge Management

\begin{tabular}{|l|l|l|}
\hline \multirow{2}{*}{ Transactional Leadership } & & Knowledge Management \\
\hline & Spearman Correlation & $.793(* *)$ \\
\cline { 2 - 3 } & Sig.(2-tailed) & 0.000 \\
\cline { 2 - 3 } & $\mathrm{N}$ & 253 \\
\hline
\end{tabular}

** Correlation is significant at the 0.01 level (2-tailed) 
Table 1 indicates that there is a significant positive relationship between relationship between transactional leadership and knowledge management. Therefore $\mathrm{H} 1$ which states that there is a significant positive relationship between transactional leadership and knowledge management is accepted in this study.

Table.2. Relationship between Transactional Leadership and Knowledge Creation

\begin{tabular}{|l|l|l|}
\hline & & Knowledge Creation \\
\hline Transactional Leadership & Pearson Correlation & $.756(* *)$ \\
\cline { 2 - 3 } & Sig.(2-tailed) & 0.000 \\
\cline { 2 - 3 } & $\mathrm{N}$ & 253 \\
\hline
\end{tabular}

** Correlation is significant at the 0.01 level (2-tailed).

Table 2 indicates that there is a significant positive relationship between relationship between transactional leadership and knowledge Creation. Therefore $\mathrm{H} 2$ which states that there is a significant positive relationship between transactional leadership and knowledge creation is accepted in this study.

Table.3. Relationship between Transactional Leadership and Knowledge Transfer

\begin{tabular}{|l|l|l|}
\hline \multirow{2}{*}{ Transactional Leadership } & Spearman Correlation & $.812(* *)$ \\
\cline { 2 - 3 } & Sig.(2-tailed) & 0.000 \\
\cline { 2 - 3 } & $\mathrm{N}$ & 253 \\
\hline
\end{tabular}

** Correlation is significant at the 0.01 level (2-tailed) 
Table 3 indicates that there is a significant positive relationship between relationship between transactional leadership and knowledge Transfer. Therefore H3 which states that there is a significant positive relationship between transactional leadership and knowledge transfer is accepted in this study.

Table.4. Relationship between Transactional Leadership and Knowledge Utilization

\begin{tabular}{|l|l|l|}
\hline & & Knowledge Utilization \\
\hline Transactional Leadership & Pearson Correlation & $.783(* *)$ \\
\cline { 2 - 3 } & Sig.(2-tailed) & 0.000 \\
\cline { 2 - 3 } & $\mathrm{N}$ & 253 \\
\hline
\end{tabular}

** Correlation is significant at the 0.01 level (2-tailed).

Table 4 indicates that there is a significant positive relationship between relationship between transactional leadership and knowledge Utilization. Therefore $\mathrm{H} 4$ which states that there is a significant positive relationship between transactional leadership and knowledge utilization is accepted in this study.

Table.5. Relationship between Transactional Leadership and Knowledge Retention

\begin{tabular}{|l|l|l|}
\hline \multirow{2}{*}{ Transactional Leadership } & & Knowledge Retention \\
\hline & Pearson Correlation & $.824(* *)$ \\
\cline { 2 - 3 } & Sig.(2-tailed) & 0.000 \\
\cline { 2 - 3 } & $\mathrm{N}$ & 253 \\
\hline
\end{tabular}

** Correlation is significant at the 0.01 level (2-tailed).

Table 5 indicates that there is a significant positive relationship between relationship between transactional leadership and knowledge Retention. Therefore H5 which states that there is a significant positive relationship between transactional leadership and knowledge retention is accepted in this study. 


\section{CONSLUSION}

In this paper the relationship between Transactional Leadership and Knowledge management was examined. Data Was Collected from 253 directors, experts, supervisors and employees of Plastic Industry in Shiraz-Iran and by using Statistical Package for Social Sciences (SPSS Version 15) for data operation.

Findings demonstrate a positive relationship between transactional leadership and knowledge management and the amount of solidarity (0.793) is meaningful in alpha level of 0.01 . This result is in the same line with findings of Riaz et al. (2014).

Regarding the second hypothesis, the obtained results demonstrate a positive and meaningful relationship between transactional leadership and Creating knowledge. The Pearson Correlation Coefficient between these two variables is 0.756 and in 0.01 level is meaningful. It can be said that Transactional leaders through strengthening tolerance of errors, effectively motivating the personnel to create knowledge in the organization and also idea management systems can increase suitable condition to create organizational knowledge.

For the third hypothesis, the obtained results manifest a positive and meaningful relationship between transactional leadership and knowledge Transfer. Pearson Correlation Coefficient between these two variables is 0.812 and is meaningful in 0.01 level.

The obtained results for the fourth hypothesis demonstrate a positive and meaningful relationship between transactional leadership and knowledge Utilization. Pearson Correlation Coefficient between these two variables is 0.783 and is meaningful in 0.01 levels. Given that transactional leadership has a special personal attention to personnel and the knowledge they obtain from it. The obtained results for the fifth hypothesis demonstrate a positive and meaningful relationship between transactional leadership and knowledge retention. Pearson Correlation Coefficient between these two variables is 0.824 and in 0.01 levels is meaningful.so Transactional leadership style has positive impact on capturing knowledge in the organization so that it can be used later.

\section{REFRENCES}

1. Abdul-Rahman, H., \& Wang, C. Preliminary approach to improve knowledge management in engineering management. Scientific Research and Essays, 2010, 5( 15), 1950-1964. 
2. Antonakis J,House R. Instrumental leadership: Measurement and extension of a transformational-transactional leadership theory. The Leadership Quarterly, 2014 : 746771.

3. Avolio, B.J., Bass, B. M., \& Jung, D. I. Re-examining the components of transformational and transactional leadership using the multi-factor leadership questionnaire. Journal of Occupational and Organizational Psychology, 1999, 72 (4), 441-62.

4. Bass, B.M. Leadership and performance beyond expectations. New York: Free Press, 1985.

5. Bass, B.M., \& Riggio, R.E. Transformational leadership (2nd ed.). Mahwah, NJ: Lawrence Erlbaum Associates Publishers, 2006.

6. Burns, J.M. Leadership. New York: Harper \& Row, 1978.

7. Crawford, C.B. Effects of transformational leadership and organizational position on knowledge management. Journal of Knowledge Management, 2005, 9 (6) : 6-16.

8. Gelard P,Boroumand Z,Mohammadi A . Relationship Between Transformational Leadership and Knowledge Management. International Journal of Information Science and Management, 2014, 12(2) : 67-82.

9. Goldoni, V., \& Oliveira, M. Knowledge management metrics in software, 2010.

10. development companies in Brazil. Journal of Knowledge Management, 14 ( 2), 301-313.

11. Hackman, Johnson, Michael, Craig. Leadership: A Communication Perspective. Long Grove, IL: Waveland Press. 2009, pp. 102-104. ISBN 1-57766-579-1.

12. Hislop, D. Knowledge management in organizations, 2nd ed. Oxford: Oxford University Press, 2009.

13. Margaryan, A., Milligan, C., \& Littlejohn, A. Validation of davenport's classification structure of knowledge-intensive processes. Journal of Knowledge Management, 2011, 15 (4), 568-581.

14. Newman, B., \& Conrad, K.W. A framework for characterizing knowledge management methods, practices, and technologies. Paper presented at the Third International Conference on practical Aspects of Knowledge Management, Basel, Switzerland, 1999.

15. Nguyen, H.N., \& Mohamed, S. Leadership behaviors, organizational culture and knowledge management practices: An empirical investigation. Journal of Management Development , 2011, 30 ( 2), 206-221. 
16. Pathirage, C. P., Amaratunga, D. G., \& Haigh R. P. Tacit knowledge and organizational performance: construction industry perspective. Journal of Knowledge Management, 2007, $11(1), 115-126$.

17. Plessis, M. Drivers of knowledge management in the corporate environment. International Journal of Information Management, 2005, 25 (3), 193-202.

18. Politis, J.D. The relationship of various leadership styles and knowledge management.

19. Leadership \& Organization Development Journal, 2001, 22 ( 8), 354-64.

20. Riaz M,Khalili M . Transformational, Transactional Leadership and Rational Decision Making in Services Providing Organizations: Moderating Role of Knowledge Management Processes. Pakistan Journal of Commerce and Social Sciences. 2014, 8(2) . 355-364.

21. Smith, R. A roadmap for knowledge management. Journal of Knowledge, 2001.

22. Management. Retrieved from www2.gca.org/knowledgetechnologies/2001/proceedings.

23. Vera D,Crossan M.Strategic Leadership and Organizational Learning.Academy of Management Review , 2004, 29(2), 222-240.

24. Yukl, G. Leadership in organizations, 5th ed. Prentice-Hall, New York. 2002.

25. Zhang, L., H. Wang, C., Xiongfei, X., Wang, \& Zhao, K. Knowledge management component in managing human resources for enterprises. Journal of Information Technology and Management, 2012, 13, 341-349.

26. Zheng, W., Yang, B., \& McLean, G.N. Linking organizational culture, structure, strategy and organizational effectiveness: Mediating role of KM. Journal of Business Research, $2010,63: 763-771$.

\section{How to cite this article:}

Ghanbari A, Abedzadeh M. Relationship between transactional leadership and knowledge management. J. Fundam. Appl. Sci., 2016, 8(2S), 1388-1398. 